\title{
In Situ Direct Displacement Information on Fault Reactivation During Fluid Injection
}

\author{
Maria Kakurina $^{1}\left[\right.$ ] Yves Guglielmi $^{2} \cdot$ Christophe Nussbaum $^{3} \cdot$ Benoît Valley $^{1}$
}

Received: 17 January 2020 / Accepted: 23 May 2020 / Published online: 10 August 2020

(c) The Author(s) 2020

\begin{abstract}
The three dimensional (3D) displacement induced by fluid injection was measured during two fault reactivation experiments conducted in carbonate rocks at the Rustrel Low Noise Underground Laboratory (LSBB URL), France, and in shale rocks at the Mont Terri Rock laboratory, Switzerland. The faults were activated by injecting high pressure fluid and using the StepRate Injection Method for Fracture In-Situ Properties, which allows a coupled pressure-flowrate-3D displacement monitoring in boreholes. Both experiments mainly show complex aseismic deformation of preexisting fractures that depend on (1) the fluid pressure variations related to chamber pressurization and leakage into the formation and (2) irreversible shear slip and opening of the reactivated fractures. Here we detail the processing of the 3D displacement data from both experiments to isolate slip vectors from the complex displacement signal. Firstly, we explain the test protocol and describe the in situ hydromechanical behavior of the borehole/fault system. Secondly, we define the methodology of the displacement data processing to isolate slip vectors with high displacement rates, which carry information about the key orientation of fault reactivation. Finally, we discuss which slip vectors can potentially be used to solve the stress inversion problem.
\end{abstract}

Keywords Geomechanics $\cdot$ Fracture reactivation $\cdot$ Displacement rate $\cdot$ Slip vector $\cdot$ Stress inversion

\section{Introduction}

Fluid injection into the rock mass may lead to either new fracture development or activation of preexisting fractures by reducing the effective normal stress and driving the plane to shear failure associated with slip (Hubbert and Rubey 1959). According to the Wallace-Bott hypothesis, the slip direction induced on fractures is a function of relative magnitudes and orientations of the principal stresses, i.e. it is parallel to the resolved shear stress (Wallace 1951; Bott 1959). Therefore, the orientation of the triggered slipped vector together with the orientation of the pre-existing fracture carries important information about the stress and can potentially be used for stress inversion. This work is the first

Maria Kakurina

maria.kakurina@unine.ch

1 University of Neuchâtel, CHYN, Emile-Argand 11, 2000 Neuchâtel, Switzerland

2 Energy Geoscience Division, Lawrence Berkeley National Laboratory, Berkeley, CA 94720, USA

3 Federal Office of Topography, Swisstopo, Seftigenstrasse 264, 3084 Wabern, Switzerland part of the research devoted to the estimation of the stress state using the slip data from a fault reactivation experiment (Kakurina 2020). Here, we discuss the information carried by the three-dimensional (3D) displacement data during the fluid injection and present a protocol to isolate a slip vector to be used for further stress inversion.

Slip induced by fluid injection is often associated with seismicity in the surrounding rock mass (Zoback and Harjes 1997; Shapiro et al. 1999; Guglielmi et al. 2008; Shapiro and Dinske 2009; Evans et al. 2012; Ellsworth 2013; McGarr 2014). The seismic slip is known to be used for stress inversion by applying the focal mechanism technique (Reasenberg 1985), which provides constraints on two potential compression-extension zones bounded by potential fault planes and defined by considering the polarities of the $\mathrm{P}$-wave first arrivals. Inversion of slip vectors deduced from the focal mechanism can provide with the orientations of the principal stresses and the stress ratio using the methods described by Gephart and Forsyth (1984); Lund and Slunga (1999); Vavryčuk (2014).

Recent studies showed direct field evidence that fluid injection can cause significant aseismic deformation, typically defined as deformation with a slip velocity that is too 
slow to generate detectable seismic waves (Cornet 2012, 2016; Zoback et al. 2012; Avouac 2015; Guglielmi et al. 2015a; Duboeuf et al. 2017; Duboeuf 2018; Cappa et al. 2018). Aseismic motions constitute an important part of the surrounding mass response during fluid injections. They were observed at large-scale experiments at geothermal sites in Soultz-sous-Forêts, France (e.g., Cornet et al. 1997; Evans et al. 2005), at meter-scale experiments at shallow depths $(\sim 300 \mathrm{~m})$ at the Mont Terri Rock Laboratory in Switzerland, Tournemire and Rustrel Low Noise Underground Laboratory (LSBB URL) in France (Guglielmi et al. 2015b; De Barros et al. 2016; Duboeuf et al. 2017), and at laboratory scale (Zoback et al. 2012; Goodfellow et al. 2015).

Both seismic and aseismic motions are controlled by coupled frictional and fluid flow behavior (Scholz 1998; Cornet 2012, 2016; Guglielmi et al. 2015a) changes in mechanical and hydrologic properties (Bird 1984; Saffer and Marone 2003) and evolving effective stress perturbations during fluid injection (Duboeuf 2018). In terms of rate-and-state friction, aseismic motion is considered to be stable (Segall 1991) and occurs when a fault strengthens during slip, demonstrating velocity strengthening behavior and rate-decreasing friction law. Seismic motion corresponds to an unstable slip, which represents a weakening behavior during slip.

The aseismic motion may occur prior to and work as a trigger for seismicity (Zoback et al. 2012; Guglielmi et al. 2015a; De Barros et al. 2016; Duboeuf et al. 2017; Duboeuf 2018; Cappa et al. 2019). The transition from aseismic to seismic behavior was explained using a slip rate dependency of fault friction (Ruina 1983; Avouac 2015; Guglielmi et al. 2015a). Guglielmi et al. (2015a) observed a slow slip rate $(4 \mathrm{~m} / \mathrm{s})$ with a high dilatancy associated with a 20 -fold increase of permeability, which was followed by faster slip $(\sim 10 \mathrm{~m} / \mathrm{s})$ with reduced dilatancy and micro-earthquakes.

Since the seismic and aseismic motions are controlled by the same coupled processes, can we use the data of aseismic motion to invert stresses? It has always been a challenge to measure an aseismic slip during fluid injection (Cornet 2016), however, nowadays it is possible by using the Step-Rate Injection Method for Fracture In-Situ Properties (SIMFIP, Guglielmi et al. 2013), which allows a coupled 3D-displacement-pressure-flowrate continuous monitoring during the fluid injection. In this paper, we use the SIMFIP data obtained during two fault reactivation experiments conducted in carbonate rocks at the Rustrel LSBB URL in France (Derode et al. 2015; Guglielmi et al. 2015a; Duboeuf 2018; Duboeuf et al. 2017; Cappa et al. 2018, 2019), and in shale rocks at the Mont Terri rock laboratory, Switzerland (Guglielmi et al. 2017; Jeanne et al. 2018, 2017; Guglielmi 2016; Guglielmi et al. 2020). Originally the fault reactivation experiments were designed for estimating the fault permeability variation during the injection (Guglielmi et al. 2017; Jeanne et al. 2018). Both experiments consisted of fluid injections into a fault damage zone to reactivate the fault planes and to measure the slip during the injection.

The 3D displacement data obtained during the fluid injections contain both reversible and irreversible responses of the surrounded rock mass. The irreversible response may be associated to either seismic and aseismic motions. Seismic motions were observed during the injection at the LSBB URL and have been already used to invert stresses using focal mechanisms (Duboeuf 2018). However, the data for both sites at LSBB and at Mont Terri mostly show aseismic motion, which relates to a complex formation response to fluid injection (Guglielmi et al. 2015a; Duboeuf et al. 2017; Duboeuf 2018; Guglielmi 2016).

Here we show how to isolate slip on preexisting fractures from the irreversible response of the rock mass, using the continuous displacements of borehole wall monitored during the injection tests. We show that most of the reversible response is related to poroelastic effects associated with the injected fluid diffusion into the formation.

Irreversible response and eventually slip on preexisting fractures are evidenced by a non-zero net displacement at the end of the test and by periods of increased displacement rate during the injection. Thus, we discuss the possibility to isolate the irreversible response of the rock mass by first applying a threshold on the displacement rate. Second, we correlate the orientation of the high displacement-rate vectors (that can be related to aseismic or seismic events) with the orientation of the tested fractures. Finally, we discuss the potential use of these vectors for a stress tensor inversion.

\section{SIMFIP Probe}

The experiment protocol for both experimental sites followed the step-rate injection method using the SIMFIP probe developed by Guglielmi et al. (2013). A $2.4 \mathrm{~m}$ test interval is isolated in a borehole between two inflatable packers (Fig. 1). In comparison to traditional hydraulic methods, the SIMFIP probe enables simultaneous monitoring of the 3D dislocation between to point anchored to the borehole wall and fluid pressure within the pressurized interval. The sampling rate is up to $1 \mathrm{kHz}$. In the experiments described in this paper, the native data were sampled at $500 \mathrm{~Hz}$. We downsample the data to reduce the noise and by trial and error we determined that $10 \mathrm{~Hz}$ is an optimal compromise between sampling rate and noise reduction. The pressure sensors range of the SIMFIP probe used in this research was $10 \mathrm{MPa}$ allowing for high-pressure Step-Rate Testing (SRT). A downhole valve operated with $\mathrm{N}_{2}$ gives control of the interval pressure and shut-in. Fluid pressure is monitored with pressure sensors below and above the packers, and in the test interval with the $0.001 \mathrm{MPa}$ accuracy. Packers sealing the interval are 
Fig. 1 a SIMFIP probe, $\mathbf{b}$ deformation unit (Guglielmi et al. 2013)

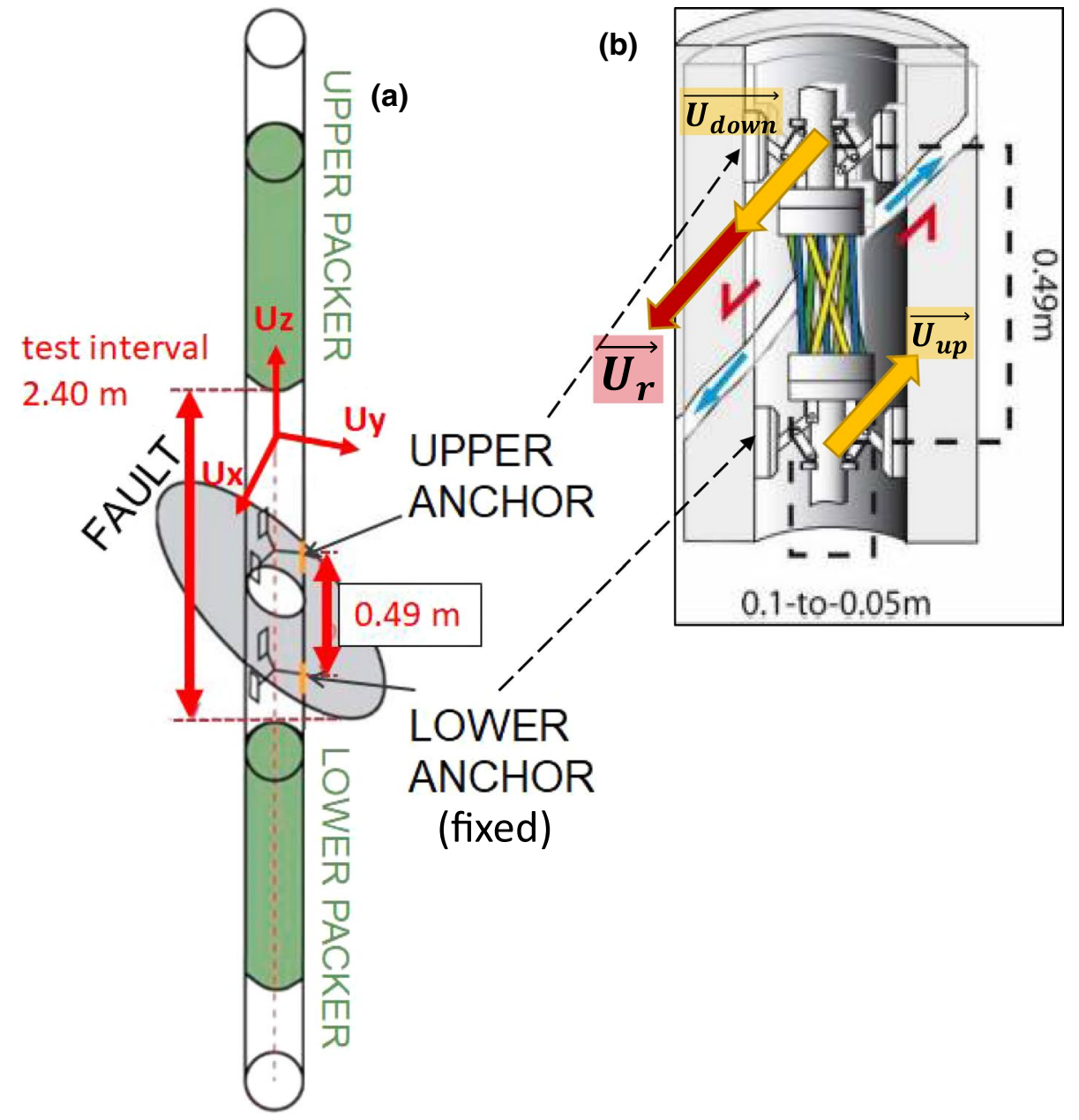

inflated with water. The 3D displacement of the injection chamber wall is monitored by a three-component extensometer centered along the axis straddling the two packers in the injection chamber (Fig. 1a). This extensometer is fixed to the borehole wall by hydraulically operated anchors. Six small-diameter and deformable steel tubes connect two rings with varying orientations - making a cylindrical cage linking the upper and lower rings. Extension between the rings is resolved from the inversion of the deformations of the six tubes. The cage used in both experiments was the same. It is $0.49 \mathrm{~m}$ long and $0.1 \mathrm{~m}$ diameter (Fig. 1b). Tube deformations are captured with six fiber optic Bragg gratings (FBG) that are attached to each tube and distributed along with one single continuous fiber that brings the sensor signals to the surfacemounted data acquisition system. An inversion algorithm is used to calculate the relative $3 \mathrm{D}$ displacements $(x$, $y$, and $z$, respectively, oriented north, west, and vertical (positive up) for shales, and oriented north, vertical (positive up), east for carbonates) of the center of the upper ring towards the center of the lower ring from the tube deformations that are continuously monitored during the test. Figure $1 \mathrm{~b}$ shows an example of measuring a relative displacement $\left(\overrightarrow{U_{\mathrm{r}}}\right)$, which represents normal slip movement along a fracture located between the anchors. The relative displacement $\left(\vec{U}_{\mathrm{r}}\right)$ is the resulting sum of the displacement of the upper anchor and lower anchor which is arbitrarily considered to be fixed. We used standard geological conception for displacement vector with a positive dip angle when the vector points below the horizontal and negative dip angle when the vector points above the horizontal. In addition, there is a reference FBG subject to ambient pressure and temperature which remains unstressed. It is used to correct the strain measurements from temperature and pressure variations in the chamber. The $6+1$ FBG is distributed along with one single continuous fiber that brings the sensor signals to the surface-mounted data acquisition system which is a MicronOptics optical interrogator (http://www.micronopti cs.com). Attached to the straddle packer system is a magnetic orientation tool used to measure the initial azimuthal positioning of the tool with a $0.1^{\circ}$ accuracy. 


\section{Geological and Experimental Settings}

At the Mont Terri site, the experiment is located at $37.2 \mathrm{~m}$ depth below the laboratory gallery floor, which corresponds to a depth below ground surface of about $300 \mathrm{~m}$, in the Opalinus Clay formation at the Mont Terri Rock laboratory, Switzerland (Fig. 2a). The laboratory is focused on studying the coupled hydrogeological, geochemical, and geomechanical processes in the Opalinus Clay formation. The exposure of Opalinus Clay in the laboratory galleries gives an excellent opportunity to investigate an unweathered clay fault system (Nussbaum et al. 2011; Jaeggi et al. 2017). The study of this formation is important because it is a potential host rock for deep nuclear waste disposal and a caprock analog for a geological carbon dioxide $\left(\mathrm{CO}_{2}\right)$ storage in deep geological reservoirs (Goodman et al. 2017).

The most deformed zone and the main tectonic structure of the Opalinus Clay, the Main Fault, crosses the galleries of the laboratory. The Main Fault consists of a complex thrust zone, about $0.8-3 \mathrm{~m}$ width, bounded by two major

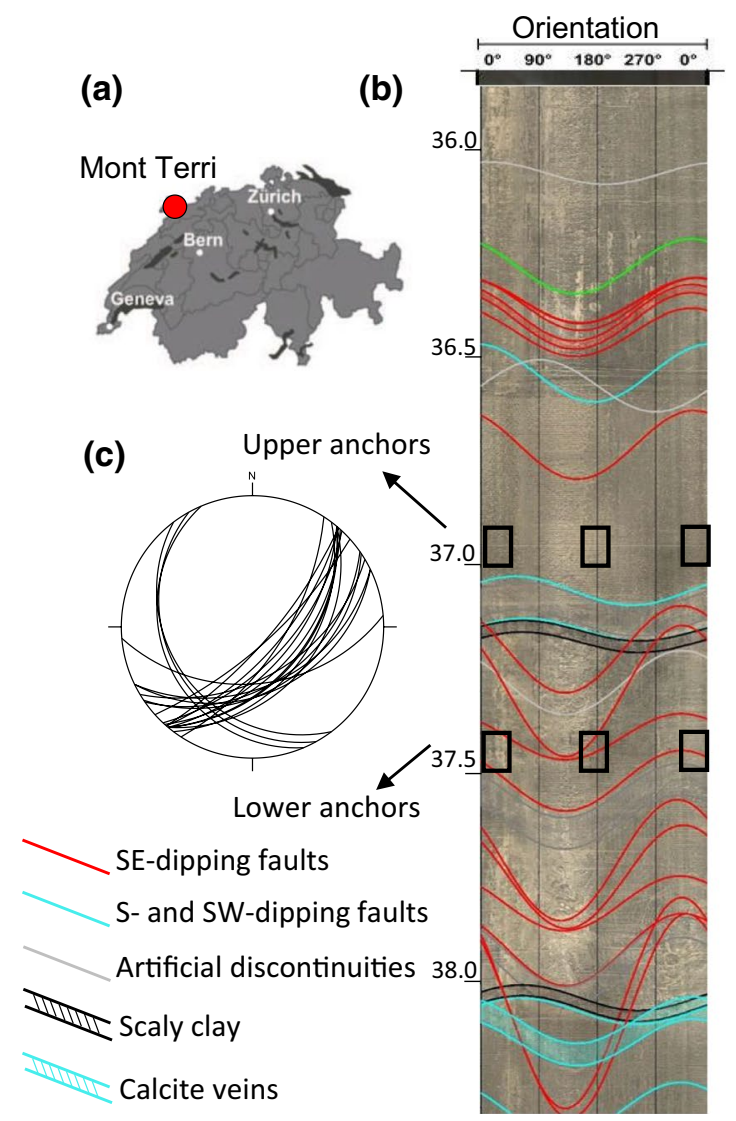

Fig. 2 Geological settings of the experimental sites. a, d Location of the Mont Terri Laboratory and of the LSBB URL, respectively. Borehole image of the intervals with geological structures at Mont Terri

fault planes with dip directions varying from $140^{\circ}$ to $165^{\circ}$ and dip angles from $40^{\circ}$ to $65^{\circ}$. The internal structure of the Main Fault is characterized by three main tectonic families of faults: (1) sub-parallel to the bedding planes faults with dip directions varying from $145^{\circ}$ to $155^{\circ}$ and dip angles from $50^{\circ}$ to $55^{\circ}$, respectively, (2) SW-dipping faults with dip angles ranging from $10^{\circ}$ to $40^{\circ}$ and sub-horizontal faults (3) E-dipping faults with dipping angles from $20^{\circ}$ to $60^{\circ}$ and steep W-dipping faults (Nussbaum et al. 2011). The variability of fault density and intersections observed at the gallery walls and on the boreholes cores make the fault zone very complex and heterogeneous. The fracture network intersects the bedding, which mainly dips towards SSE with a dip angle evolving from $30^{\circ}$ to $50^{\circ}$. The stress state which is currently considered in Mont Terri was synthesized by Martin and Lanyon (2003) from different stress testing methods: $\sigma_{1}=6-7 \mathrm{MPa}$ with $210^{\circ}$ trend and $70^{\circ}$ plunge to sub-vertical, $\sigma_{2}=4-5 \mathrm{MPa}$ with $320^{\circ}$ trend and $7^{\circ}$ plunge, and $\sigma_{3}=0.6-2 \mathrm{MPa}$ with $052^{\circ}$ trend and subhorizontal to $18^{\circ}$ plunge.

The Fault Slip experiment, conducted in the Mont Terri Rock Laboratory, consisted of injecting fluid into sealed

(d)

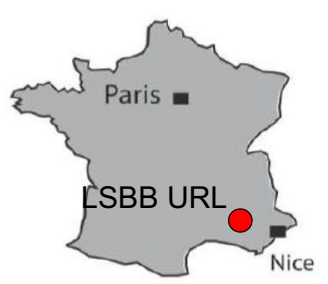

(f)

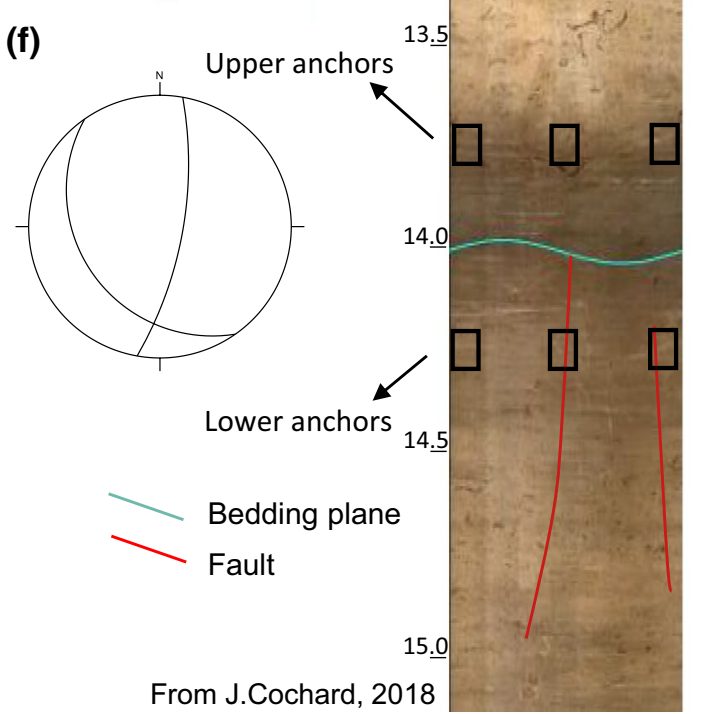

(b) and at the LSBB URL (d). Stereonet with the structures in the interval $-\mathbf{c}$ at Mont Terri and $\mathbf{f}$ at the LSBB URL 
intervals in upper, middle, and lower parts of the Main Fault to eventually trigger a local fault reactivation (Guglielmi 2016; Guglielmi et al. 2017). Here we focus on one injection test conducted between 35.85 and 38.33 m depth below the gallery floor (Fig. 2b). The depth of $37.2 \mathrm{~m}$ corresponds to the center of the displacement cage in the interval. In this interval, the injection was performed $6.5 \mathrm{~m}$ above the Main Fault in its damage zone (Guglielmi 2016; Kakurina 2020). The borehole was initially dry (no flow was observed after drilling). After deployment of the probe and sealing of the injection interval by packer inflation, the injection chamber was saturated with a fluid with equivalent chemistry to the formation fluid and to an initial pressure of $0.6 \mathrm{MPa}$ to be in equilibrium with the local formation pressure (Guglielmi 2016; Guglielmi et al. 2020).

The injection interval intersects a set of fractures subparallel to the bedding planes with the dip directions and dip angles varying from $123^{\circ}$ to $154^{\circ}$ and $36^{\circ}$ to $74^{\circ}$, respectively, three SW-dipping fractures with an average orientation of $240^{\circ} / 23^{\circ}$ and one S-dipping fault oriented $174^{\circ} / 43^{\circ}$ (Fig. 2b, c). The zone located between the two anchors of the displacement cage consists of two SW-dipping fractures $\left(233^{\circ} / 25^{\circ}\right.$ and $\left.247^{\circ} / 20^{\circ}\right)$ with a $2 \mathrm{~cm}$ thick layer of scaly clays (Nussbaum et al. 2011; Laurich et al. 2015) located in the upper part of the displacement cage, and five SE-dipping fractures $\left(130^{\circ} / 55^{\circ}, 130^{\circ} / 46^{\circ}, 131^{\circ} / 65^{\circ}, 130^{\circ} / 37^{\circ}, 130^{\circ} / 45^{\circ}\right)$ in the lower part of the cage.

In carbonates, the experiment is located at $280 \mathrm{~m}$ depth in the galleries of the Rustrel Low Noise Underground Laboratory (LSBB URL, http://lsbbnew.prod.lamp.cnrs.fr) in the southeast of France sedimentary basin (Fig. 2d). The laboratory is focused on the investigation of coupled ThermoHydro-Mechanical-Chemical (THMC) processes in porous fractured platform carbonates. The laboratory galleries give excellent access to a particular environment of unaltered fractured Cretaceous limestone (Urgonian facies), which are regarded as: (1) an exceptional access to the unsaturated zone of a large karstic aquifer, (2) an analog to the Middle East carbonate oil and gas reservoirs, (3) the area of major seismogenic faults in Provence, southeastern France.

The experiment was conducted in a $40 \mathrm{~m} \times 20 \mathrm{~m} \times 20 \mathrm{~m}$ volume in the fractured zone, which mainly includes bedding planes with dip directions from $200^{\circ}$ to $225^{\circ}$ and dip angles from $20^{\circ}$ to $35^{\circ}$, E- and W-dipping steep fractures and S-dipping fractures with dip angles from $20^{\circ}$ to $50^{\circ}$ fractures (Cochard 2018; Duboeuf 2018). The experimental area has a strong heterogeneity in the rock quality and hydraulic properties (Jeanne et al. 2012).

The state of stress was estimated from hydraulic tests on preexisting fractures (HTPF) during a previous experiment using a straddle-packer probe and taking into account topographic stresses by Guglielmi et al. (2015a) and from microseismic events using focal mechanisms inversion by
Duboeuf (2018). The regional stress state was estimated to be: $\sigma_{1}=6 \pm 0.4 \mathrm{MPa}$ is sub-vertical, $\sigma_{2}=5 \pm 0.5 \mathrm{MPa}$ is subhorizontal and trending $20^{\circ} \pm 20^{\circ}$, and $\sigma_{3}=3 \pm 1 \mathrm{MPa}$ is subhorizontal and trending $110^{\circ} \pm 20^{\circ}$ (Guglielmi et al. 2015a).

The injection test was conducted between 12.65 and $15.13 \mathrm{~m}$ depth below the gallery floor, 20 away from the Main Damage Zone (Fig. 2e, Cochard 2018; Duboeuf 2018; Jeanne et al. 2012). The center of the deformation unit is at the depth of $14 \mathrm{~m}$ across a bedding plane oriented $235^{\circ} / 26^{\circ}$, which separates two different rock facies in the interval. The facies located above the bedding plane is a low fractured grainstone with a porosity of $12-16 \%$. The facies below the bedding place is a highly fractured packstone with low porosity $(<3 \%)$. In addition, the interval is clearly intersected by a sub-vertical E-dipping fracture (Cochard 2018, Fig. 2f).

The stress state using focal mechanisms from test 9 showed differences from the regional stress state with $\sigma_{1}$ trending $225^{\circ} \pm 20^{\circ}$ and plunging $40^{\circ} \pm 10^{\circ}, \sigma_{2}$ sub-horizontal trending $330^{\circ} \pm 40^{\circ}$ and $\sigma_{3}$ trending $210^{\circ} \pm 10^{\circ}$ and plunging $80^{\circ} \pm 5^{\circ}$ (Duboeuf 2018). The stress computed using the focal mechanisms is different from the one computed by Guglielmi et al. (2015a). Duboeuf (2018) propose that the reason for the discrepancy is stress change induced by aseismic slip prior to seismic events.

\section{Injection Protocols of the Conducted Tests and First Interpretation of the Data}

This paper focuses on pressure step-up injection tests that were part of the hydraulic stimulation experiments conducted with an engine pump at Mont Terri (Guglielmi 2016; Kakurina 2020) and at LSBB (Duboeuf 2018; Duboeuf et al. 2017).

For both engine pump experiments pressure is increased stepwise in the intervals until a significant increase in the injected flow rate is measured. This pressure is a proxy to a fracture opening pressure.

\subsection{Injection Protocols and the General Analysis of the Flowrate-Pressure-Displacement Data}

\subsubsection{Mont Terri site}

The SRT injection at the Mont Terri site lasted $800 \mathrm{~s}$ (Fig. 3a). The injection includes three initial steps that increased the pressure to $3.9 \mathrm{MPa}$. Then, five successive pressure steps of $0.5 \mathrm{MPa}$ each were applied. Each pressure step was about one minute long. The highest injection pressure step is associated with the dramatic increase of flowrate from small oscillations to $>20 \mathrm{~L} / \mathrm{min}$. The total amount of injected fluid during this step is $100 \mathrm{~L}$. The SRT injection 


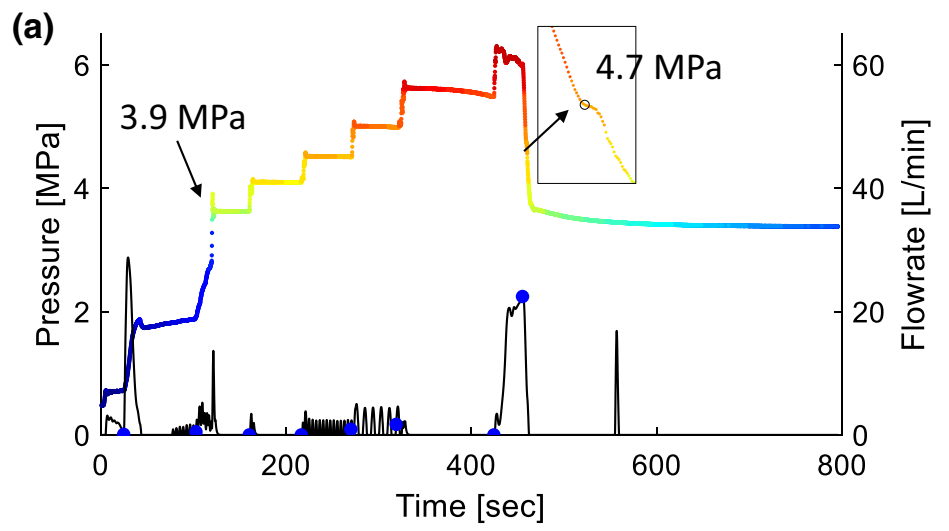

(d)

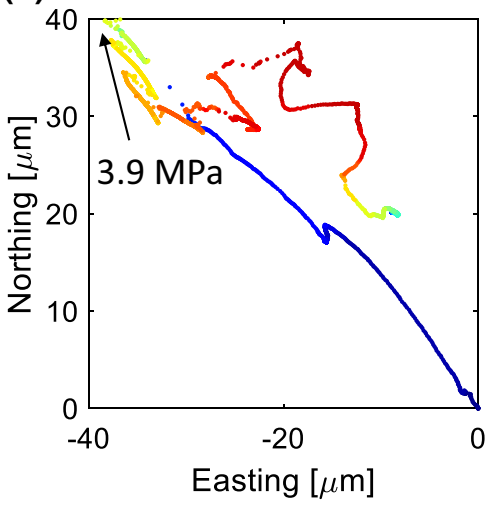

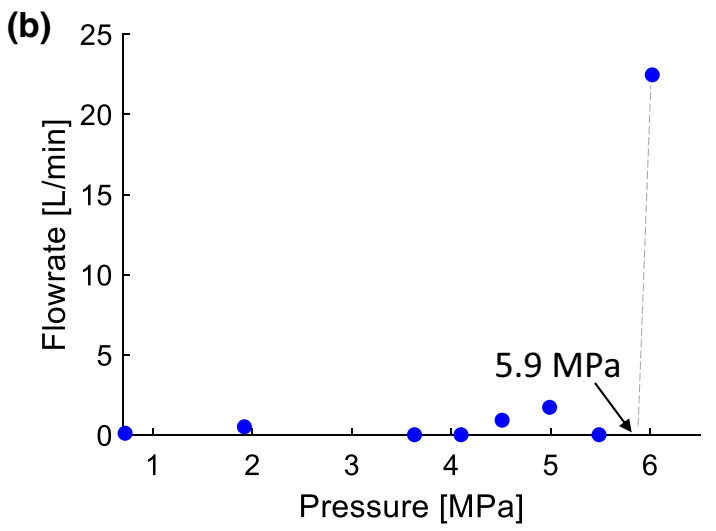

(c)

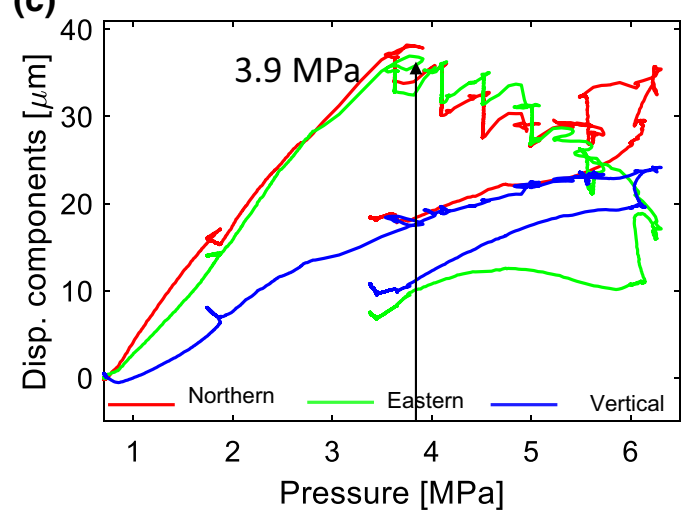

Fig. 3 a Coupled pressure-flowrate variation during the SRT injection at Mont Terri, color corresponds to the pressure variation, b flowrate steady-state vs. pressure, $\mathbf{c}$ variation of the three components of 3D displacement vs. pressure, $\mathbf{d} 2 \mathrm{D}$ view on Easting vs. Northing displacement components, and e 2D view on Easting vs. Vertical displacement components (color figure online) ended with a shut-in pressure to constrain a fracture closure pressure, which is the pressure at which the flowrate falls back to zero (Guglielmi 2016).

The flowrate vs pressure is given in Fig. 3b. The flowrate measurements (dark blue markers in Fig. 3a and b) are taken at the end of each pressure step. Figure $3 b$ shows that there is a significant flow rate of up to $23 \mathrm{~L} / \mathrm{min}$ during the pressure increase at 5.8 MPa.

The linear response of the displacement-vs-pressure is defined by plotting the three components of the displacement versus the injected pressure measured into the chamber. This linear response mainly represents a reversible response of the rock mass in the borehole nearfield to the fluid pressure increase in the borehole. Figure $3 \mathrm{c}$ shows that the three components of the displacement have a quasilinear trend only up to $3.9 \mathrm{MPa}$ and a more complex response above it. Figure 3d and e show that this quasilinear trend has a NE-SW direction which is mostly normal to the SEdipping fractures and the bedding. Considering that this $\mathrm{NE}-\mathrm{SW}$ trend is observed since the beginning of the injection and the SE-dipping orientation of the bedding planes, we assume that the displacements below 3.9 MPa indicate the reversible response of the interval. This reversible response can be modeled using a fully coupled hydromechanical elastic model (Jeanne et al. 2017).

The flowrate oscillation during the fifth and the sixths pressure steps up to $5 \mathrm{~L} / \mathrm{min}$ above $4.2 \mathrm{MPa}$ might be related to the reopening of reactivated fractures. These pressure values are consistent with the shut-in pressures range of 4.3-4.5 $\mathrm{MPa}$ defined during the manual pump performed prior to studied SRT varies (Kakurina 2020) and with the pressure kink at 4.7 MPa observed during the shut-in of this SRT.

\subsubsection{LSBB URL}

The high-pressure SRT injection at the LSBB site lasted significantly longer than in shales, to approximately $1800 \mathrm{~s}$ (Fig. 4a). The initial pressure in the chamber was $1 \mathrm{MPa}$. The test consisted of 12 pressure steps with a pressure increment of 0.5 MPa. Each pressure step lasted $1 \mathrm{~min}$, except for the pressure step from 4.4 to $4.7 \mathrm{MPa}$ that lasted about $10 \mathrm{~min}$. The maximum injected pressure during the final step is $5.9 \mathrm{MPa}$, which had a maximum flow rate of $13.3 \mathrm{~L} / \mathrm{min}$. 
(a)

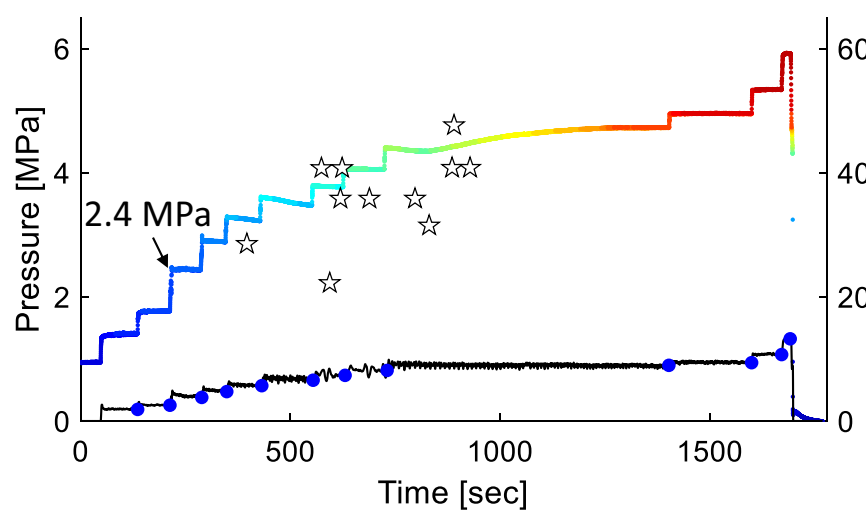

(d)

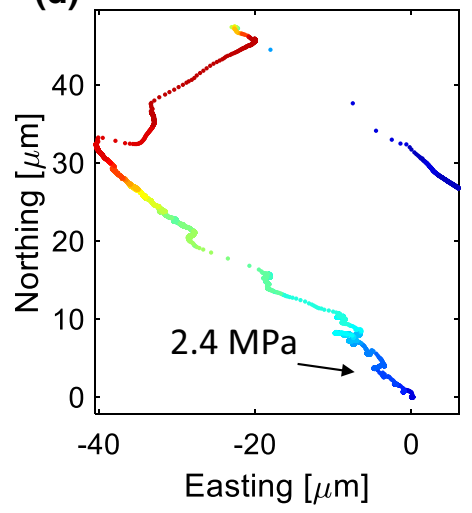

(e)

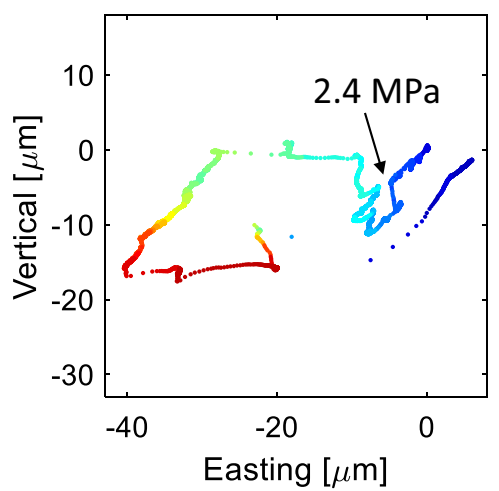

(b)

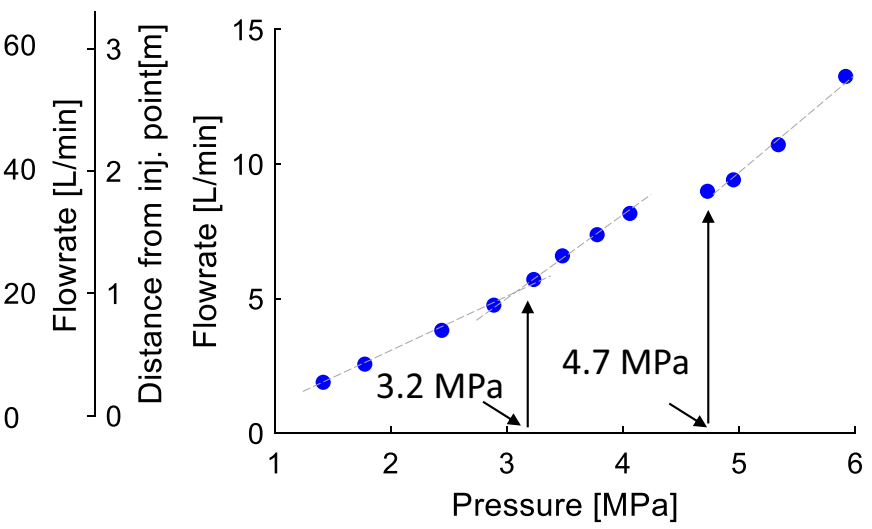

(c)

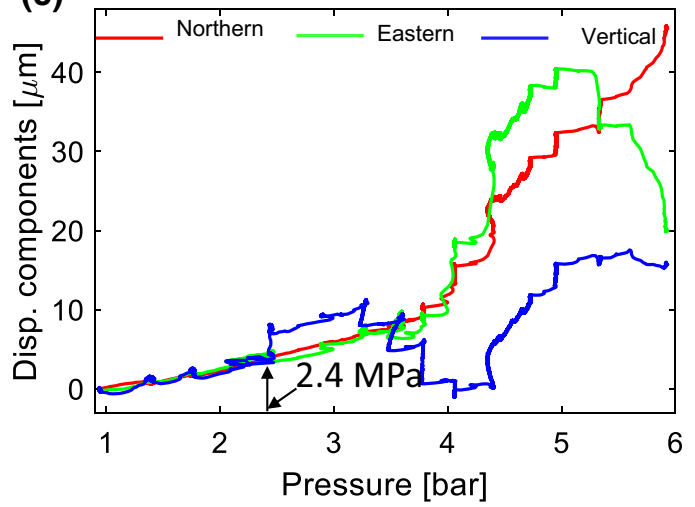

Fig. 4 a Coupled pressure-flowrate variation during the SRT injection at LSBB, color corresponds to the pressure variation, stars correspond to seismic events, b flowrate steady-state vs. pressure, c varia-

A total volume of $700 \mathrm{~L}$ was injected during this test. The SRT injection in carbonates ended by bleeding the chamber, which did not allow observation of the shut-in pressure.

The injection in carbonates induced seismic events, which were analyzed in detail by Duboeuf (2018) and Duboeuf et al. (2017). The first seismic event occurred at the pressure greater than $3.2 \mathrm{MPa}$ and $1.5 \mathrm{~m}$ away from the injection chamber. The orientation of the focal mechanism could not be defined due to a small magnitude of the event. Later, a sequence of seismic events occurred at the pressure range of 3.8-4.6 MPa, which indicated a primarily strike-slip motion on the bedding plane with sometimes a normal and reverse component. All the events were located between 1 and $3 \mathrm{~m}$ away from the injection chamber (Duboeuf 2018; Duboeuf et al. 2017).

The flowrate measurements (dark blue markers in Fig. 4a and b) taken at the end of each pressure step and representing quasi-steady-state conditions demonstrate different behaviors for high-permeable carbonates in comparison to low permeable clays. Figure $4 \mathrm{~b}$ shows that the flowrate linearly increases until 3.2 MPa. Above tion of three components of 3D displacement vs. pressure, $\mathbf{d} 2 \mathrm{D}$ view on Easting vs. Northing displacement components, and e 2D view on Easting vs. Vertical displacement components (color figure online)

3.2 $\mathrm{MPa}$, there are two changes in the flowrate increasing trend-from 3.2 until 4.1 MPa and from 4.7 until 5.9 MPa, respectively.

Figure $4 \mathrm{c}$ shows that the linear displacement-vs-pressure response is observed until 2.4 MPa. We assume that it corresponds to the reversible response of the interval, which mostly has a NW-SE trend (Fig. 4d, e) and aligned with the strike of the bedding plane. Figure $4 \mathrm{~d}$ and e show that most complexity comes from the variation of the vertical component of the displacements, which might be related to the presence of the sub-vertical fracture in the injection interval.

Horizontal displacements between 3.7 and $4.4 \mathrm{MPa}$ (Fig. 4e, green, and light blue markers) have a WNW-ESE trend. This trend is normal to the sub-vertical fracture and associated with the first injectivity increase (Fig. 4b), and therefore, might correspond to the fracture opening. The displacements from 4.4 MPa until 4.95 MPa (Fig. 4e and $\mathrm{d}$, light green, yellow, orange markers) are mostly oriented towards NW or sub-vertically. At 4.95 MPa the displacement trend rotates towards SW-NE (Fig. 4e, d, dark red markers) and is associated with the second increase of the flowrate 
(Fig. 4b). These displacements aligned with the strike-slip on a bedding plane.

\section{The Protocol for Pre-processing the Displacement Data to Identify Slip Vectors}

The displacement response for both shale rocks at Mont Terri and carbonate rocks at LSBB intervals is complex (Figs. 3c-e and $4 \mathrm{c}-\mathrm{e}$ ). This complexity of the data comes from the sum of the responses of the complex system including (1) the probe borehole interaction, (2) the deformation associated with stress concentration at the borehole wall and background stress, (3) fluid diffusion from the injection interval into the formation. All these processes are influenced by the rock properties including the fractures. To simplify the displacement signal complexity and to define the key orientations that could be used for further stress inversion analyses, the following protocol has been applied. The goal of the protocol was thus not to fully explain the complex rock mass response to injection, but to extract deformation events that could clearly be associated to fracture slip.

The protocol consists of several steps, which are explained in detail below. Firstly, we isolate the time windows of constant pressure steps to avoid the influence of pump oscillation signal. Secondly, we defined limits of linear displacement-vs-pressure response to later estimate the threshold between displacement rates during reversible and irreversible deformation. Thirdly, we apply the threshold to the displacement rates measured during the constant pressure steps to identify the steps, which include higher displacement rates and may indicate a fracture slip.

\subsection{Isolating Time Windows when the Injection Pressure in the Chamber is Constant}

The tests were performed as a pressure-controlled injection with increasing pressure steps. Mobilization of the pumping system is required to climb from one pressure step to the next. During this rapid pressure increase strong deformation occurs which likely reflects the superposition of multiple processes. This deformation is influenced by the hydraulic response of the probe borehole system. Extracting with confidence the signal that is capturing fracture slip during these phases is hazardous. Therefore, we focused our analyses on the time window when the pressure is maintained constant (Fig. 5 cyan markers, a-Mont Terri, b-LSBB URL). These time windows were determined manually on the recorded signal. They start from the time a quasi-constant pressure is reached after the pressure has been step increased and they end at the onset of the next step pressure increase.

\subsection{Identification of a Pseudo-linear Displacement-vs-Pressure Response}

In Figs. $3 c$ and $4 c$, we show that at Mont Terri the linear response of displacement is observed until $3.9 \mathrm{MPa}$ (pressure steps 1 and 2) and at the LSBB URL the linearity is preserved until 2.4 MPa (pressure steps 1, 2 and 3). We do not expect any dislocation related to fracture slip to occur during this period. The curve kink when losing linearity highlights the onset of a significant irreversible response of the formation (Figs. 3c, 4c). Thus, the steps following this kink which respectively are steps 3 to 9 in the shale case and steps 4 to 13 in the carbonate case might contain slip events.

\subsection{Identification of the Highest Displacement Rate}

During the time windows when the pressure is constant in the chamber, we assume that primarily two type of processes occur: (1) pressure diffusion into the formation (a)

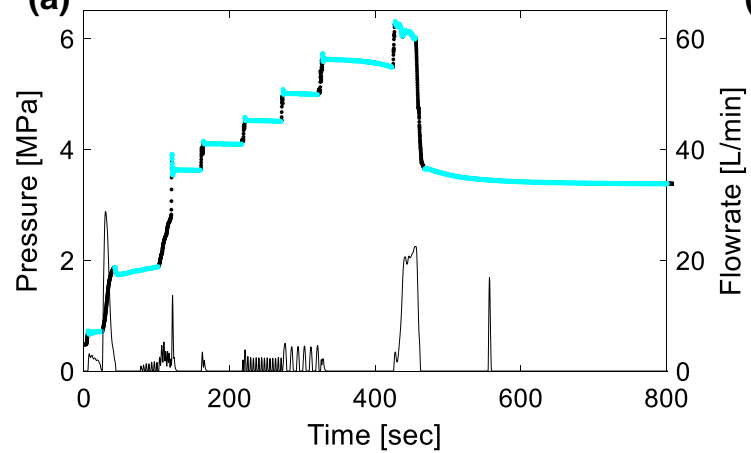

(b)

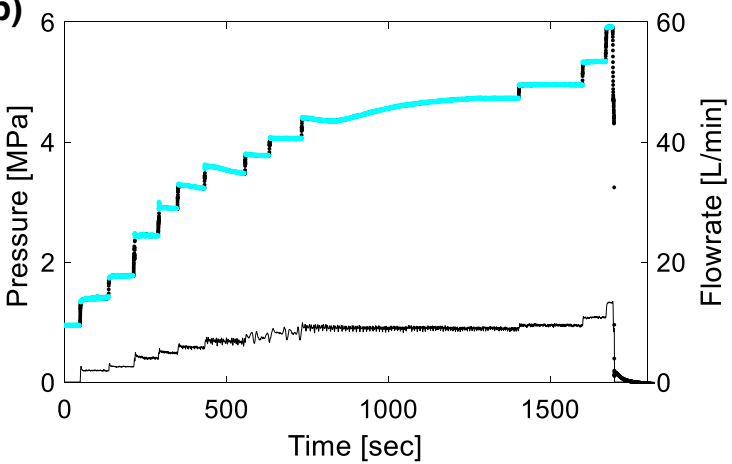

Fig. 5 The coupled pressure-flowrate variations with monitored pressure steps highlighted in cyan for a Mont Terri and b LSBB (color figure online) 
that induced progressive and slow deformation and (2) fracture rupture and slip that induced sudden and rapid displacement. Being interested in the second process, we decided to analyze the displacement rate during these time windows. The displacement rate is obtained by measuring the magnitude of the displacement every $0.1 \mathrm{~s}$ at each time window (Fig. 6). Maximum displacements rates of $2 \mu \mathrm{m} / \mathrm{s}$ (pressure steps 1 and 2 at Mont Terri, Fig. 6a) and $2.4 \mu \mathrm{m} / \mathrm{s}$ (pressure steps 1,2 , and 3 at the LSBB URL, Fig. 6 b) are observed at the low-pressure steps and characterize reversible poroelastic strain rates. Significantly higher rates up to about $8-9 \mu \mathrm{m} / \mathrm{s}$ are observed in steps 3,7 , and 8 for shales, and in steps 4, 10, 12, and 13 for carbonates (Figs. 6a, b).

It is known that fluid injection and kinematic faults interactions during multiple fault reactivations can perturb the surrounding stresses (Schoenball et al. 2014; Barton and Zoback 1994; Lei and Gao 2019). Therefore, we assume that only the first slip event, which corresponds to the beginning of the non-reversible deformation, is controlled by the unperturbed background stress and we propose that it can be considered for the stress inversion considerations. Thus, here we discuss only first steps with higher rates: step 3 for the Mont Terri site and step 4 for the LSBB URL. The results of other steps are given in Appendix (Tables 1 and 2 for the Mont Terri and LSBB site, respectively) and discussed in detail in Kakurina (2020).

\section{Analysis of the Slip Vectors Orientation}

Figure 7 shows the stereonets with raw data of the displacements (a), displacement after processing (b), and the isolated slip vectors (c). Each point on a raw data stereonet corresponds to a vector calculated between two positions of the SIMFIP sensor at a $0.1 \mathrm{~s}$ interval. Displacements after the processing corresponding to the displacements with a high rate from the first step representing irreversible response defined in Fig. 6 (Step 3 for Mont Terri and Step 4 for the LSBB URL). Such a high rate displacement vector will be called a 'displacement event'. The displacement event is regarded as 'slip-dominant' displacement and not precisely the displacement of pure slip motion. The displacement event still contains complex displacement components originated from other than pure slip, although as shown on the stereonet of Fig. $7 \mathrm{~b}$ some vectors align on fracture plane and can potentially represent almost purely slip motion.

\subsection{Mont Terri Site}

Six displacement events occurred as the pressure dropped from 3.9 to $3.5 \mathrm{MPa}$. The sequence of the first three displacement events occurred at the pressures $>3.8 \mathrm{MPa}$ in the same ENE direction (Fig. 7b, blue). An average orientation of these vectors $\left(075^{\circ} / 25^{\circ}\right)$ is aligned with the SE dipping fractures in the interval. These events indicate the end of the compliant response of the interval and the beginning of
Fig. 6 Variation of the displacement rates at each pressure step (boxplots). Light blue rectangles represent the pressure steps with the linear pressure-displacement behavior, dashed grey line-a threshold. Displacements rates highlighted in red ellipsoid exceed the threshold. Star represents the capturing of the seismic events (color figure online) (a)

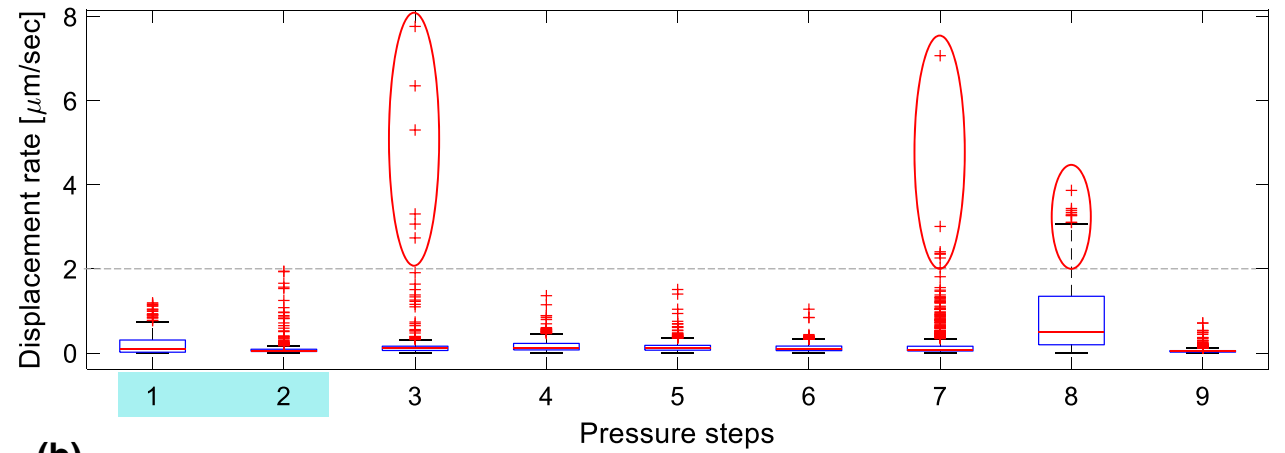

(b)

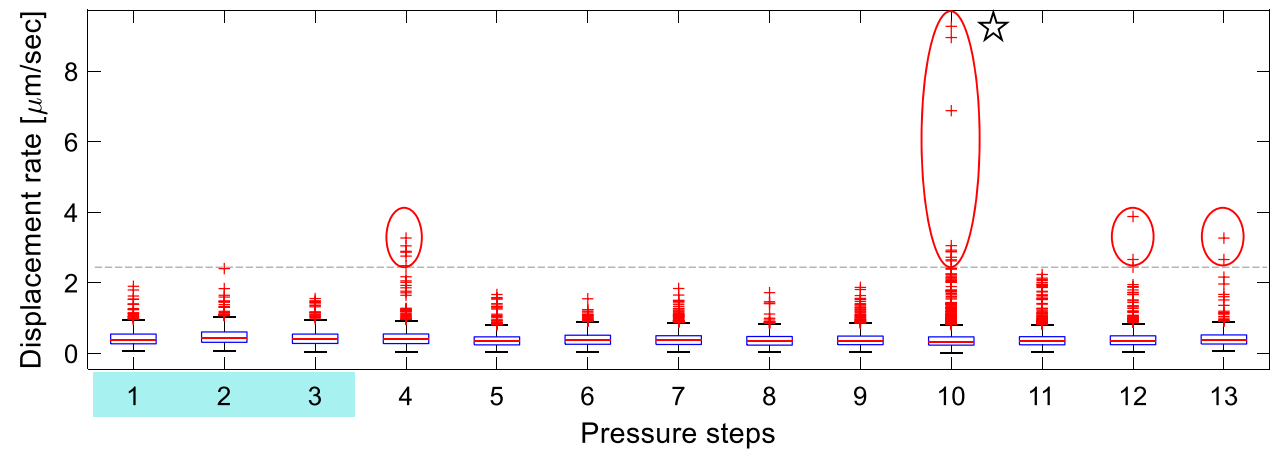


some irreversible deformation. The second sequence corresponds to the displacement events 4-5. It is characterized by the rotation of the displacement vectors towards SW. The rotated vectors 4 and 5 are parallel to the intersection line between the SE-dipping fractures and the SW-dipping fractures. The event 6 of the step rotates towards normal to the SE-dipping fractures. This orientation is consistent with an overall NW-SE trend, observed during this pressure step among the displacements with the low displacement rate $(<2 \mu \mathrm{m} / \mathrm{s})$ and with an orientation of the elastic response of the media. The displacement events 1-5 demonstrate normal slip (positive dip angle of $\left(\overrightarrow{U_{\mathrm{r}}}\right)$, when the event 6 demonstrate reverse slip (negative dip angle of $\left(\overrightarrow{U_{\mathrm{r}}}\right)$ ).

\subsection{LSBB URL}

Six continuous displacements events of a step 4 occur in a pressure range of 2.42-2.47 MPa (Fig. 7). Though the orientation of all the events is sub-vertical, it is possible to observe that the events 1-3 are mostly dipping NE (yellow, orange and dark red in Fig. 7b), when the events 4-6 show the rotation from NW to ESE (Fig. 1.10c). All the displacement events demonstrate a normal slip movement and can be potentially aligned with the sub-vertical fracture oriented $110^{\circ} / 70^{\circ}$. There is no seismicity occurring during this pressure step.

\section{Discussion}

The evolution of flow rate, pressure, and 3D displacement of the borehole wall during fluid injection from two fault reactivation experiments conducted at Mont Terri and the LSBB URL shows a complex response due to the superposition of multiple effects. We were interested in isolating fracture slip directions that we can interpret for stress estimation using the Wallace-Bott hypothesis. We developed a new protocol to isolate these slip vectors despite the complexity of the signal. The protocol is based on the extraction of displacement events that display high displacement rate during constant pressure periods. This approach is justified by the conceptualization of the main processes happening in the chamber during fluid injection. We compared the response to the fluid injection of fractured shales and carbonates and discussed which slip vectors can be driven by the current stress state according to the Wallace-Bott hypothesis.

\subsection{Borehole Near Field Response to Fluid Injection}

The analyses of our data at Mont Terri and at the LSBB URL allowed identifying two main processes during injection in the open hole interval sealed sections (Fig. 8). First, we observed a linear displacement-vs-pressure relationship that we interpret as an elastic response of the wellbore wall to pressurization (Fig. 8). Such a linear response is wellisolated for both Mont Terri and LSBB sites as a slow and progressive deformation in reaction to the borehole wall pressurization. The pressurization and the injected fluid diffusion into the formation during this linear response does not trigger slip events. We used the measured displacement rates during this period as a threshold to identify faster displacements that occurred in the chamber. The threshold was defined as the maximum displacement rate measured during the elastic response of the chamber. Later and at higher injection pressure, several high displacement rate events occur. To avoid any misinterpretation of high rate increases, we chose to only pick these displacement events during the periods of time when the pressure in the interval is maintained constant. Thus, these events cannot be explained by rapid pressurization, pump oscillation, or other complex response of the injection pump-downhole probe-borehole system. The displacement events represent non-reversible deformation induced by a fracture activation. The high displacement rate of these events indicates their rapid and sudden occurrence, which we interpret as fault rupture. Some of them correlate with the observed induced seismicity. This is the second important process that we conceptualized in Fig. 8. Later during the injection, continuing pressure diffusion and fault activation lead to mechanical interactions in the system, which perturb the surrounded stresses and results in a complex response of the chamber.

\subsection{Isolating Displacement Events on Natural Reactivated Fractures}

Three and four pressure windows including displacement events were identified for Mont Terri and for the LSBB URL, respectively, by applying the data processing protocol, described in this paper.

The normal and shear stresses on a fracture that define the failure of the fracture are controlled by the background stress. The background stress causes slip on a fracture which is consistent with the orientation of the resolved shear stress according to the Wallace-Bott hypothesis (Kakurina et al. 2019). The injection reduces the effective normal stress on a fracture until it reaches the Mohr-Coulomb failure criteria and thus the fracture slips. We assumed that the activation of the fracture occurs faster than the stress perturbation due to the poromechanical effects. This assumption is based on the consideration of higher permeability of fractures in shales rocks at the Mont Terri site and in carbonate rocks at the LSBB site than the permeability of the rock mass. When more than one slip event is detected, we considered that a succession of events will increase the deformation in the chamber, which leads to an increase of stress perturbation along with the fracture and stress concentration on fracture 


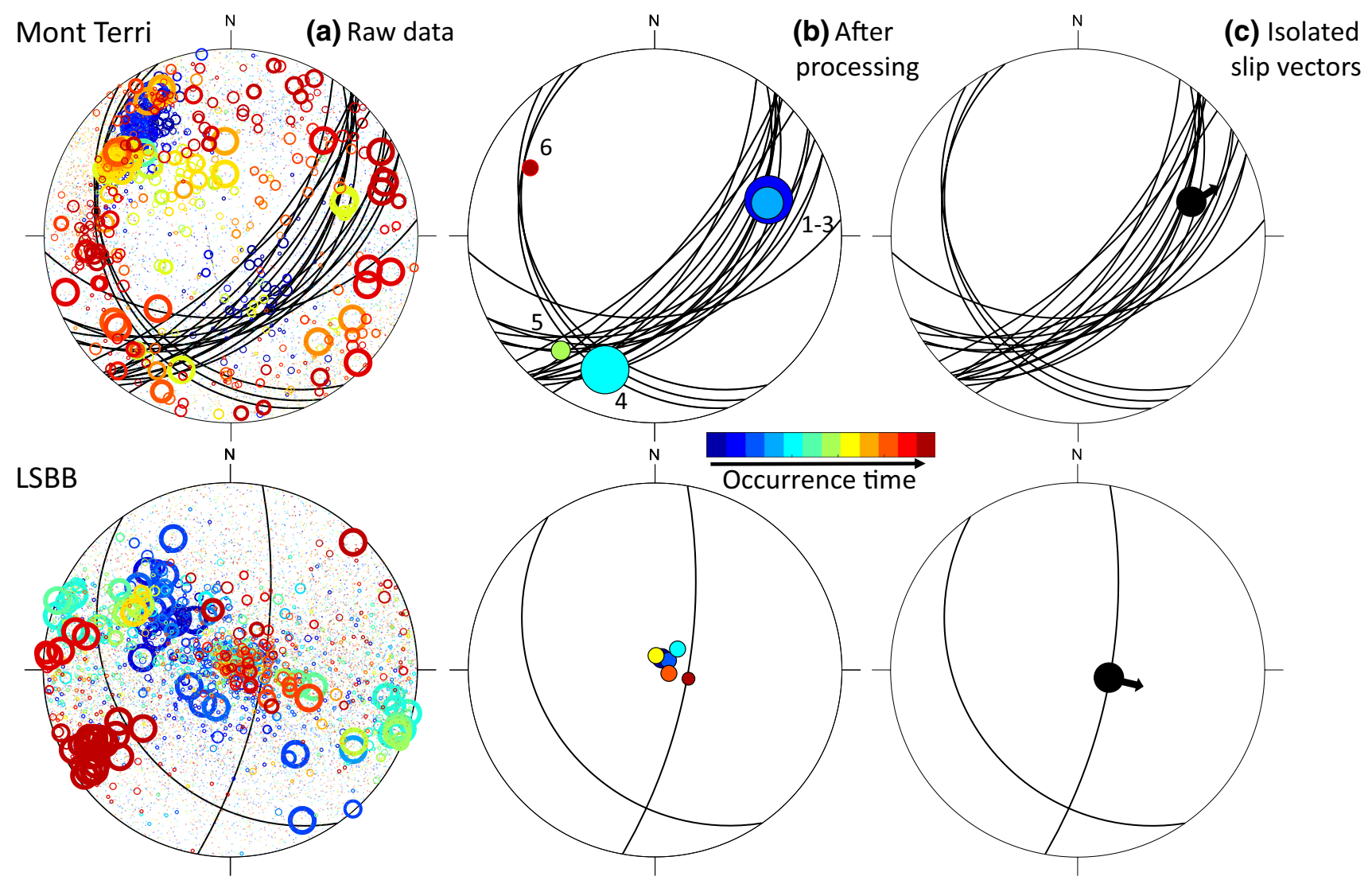

Fig. 7 Processing of the displacement data. a Projection of the raw displacement vectors captured every $10 \mathrm{~Hz}$. The color is related to the pressure at which the displacement is measured (see Figs 3 and 4). b displacement events after applying the protocol. The color is related to the occurrence time. The scaling of the markers for both left and middle plots corresponds to the relative norm of the displacement vector magnitude. c Isolated vector after processing (color figure online) tips. Therefore, we assumed that the first slip event was the most consistent with the background stress and did not use the following displacements events in this work. At both experimental sites the first measured slip is aseismic.

At Mont Terri the first three displacement events with an average orientation $075^{\circ} / 25^{\circ}$ are aligned with SE-dipping fractures. However, the interval also includes another SWdipping family. Fractures from both families occur between the anchors, where the displacement magnitude captured by the SIMFIP is the strongest (Kakurina 2020). The existence of fractures with different orientations complicates the analysis. Consequently, the first displacement events do not keep the same orientation but are quickly replaced by a vector, which is parallel to the intersection line between the SE-dipping and SW-dipping fractures. The rotation of the orientation of the events occurred because of the mechanical interactions between closely spaced faults, which can strongly influence the local stress and slip direction (Pollard et al. 1993; Maerten 2000; Nieto-Samaniego and AlanizAlvarez 1997; Lisle 2013). Pascal (2002) demonstrated that the slip is strongly perturbed close to the line intersection of two faults. Maerten (2000) showed that this perturbed slip tended to be parallel to this intersection line. Displacements parallel to the intersection line are also observed among the displacement events, occurring at the pressures > 5.5 MPa, which with an increase of flowrate rotate towards being normal to the SE-dipping fractures.

Even though the first displacement event is aligned with the SE fractures, one may ask if this event could correspond to the opening of the SW-dipping fractures. Considering the regional stress state in Mont Terri (Martin and Lanyon 2003) and low dip angle of the SW-dipping fractures, we estimated that the normal stress on the SW-dipping fractures is higher than on the SE-dipping fractures, which prevents the SWdipping fractures from slipping first. Moreover, the slip orientation on the SE-dipping fractures is consistent with the first slip event, occurring during the pressurization of the interval located $3 \mathrm{~m}$ below the analyzed test. Guglielmi et al. (2020) showed that this slip, occurring on a SE-dipping fracture $\left(136^{\circ} / 32^{\circ}\right)$, is favorable for activation under the stress state obtained by Martin and Lanyon (2003). Finally, the SW-dipping fractures are typically sealed with calcite and celestite (Nussbaum et al. 2011), which adds cohesion and prevents the reactivation of these fractures. Therefore, we 
Fig. 8 Conceptual model of the main processes happening during fluid injection

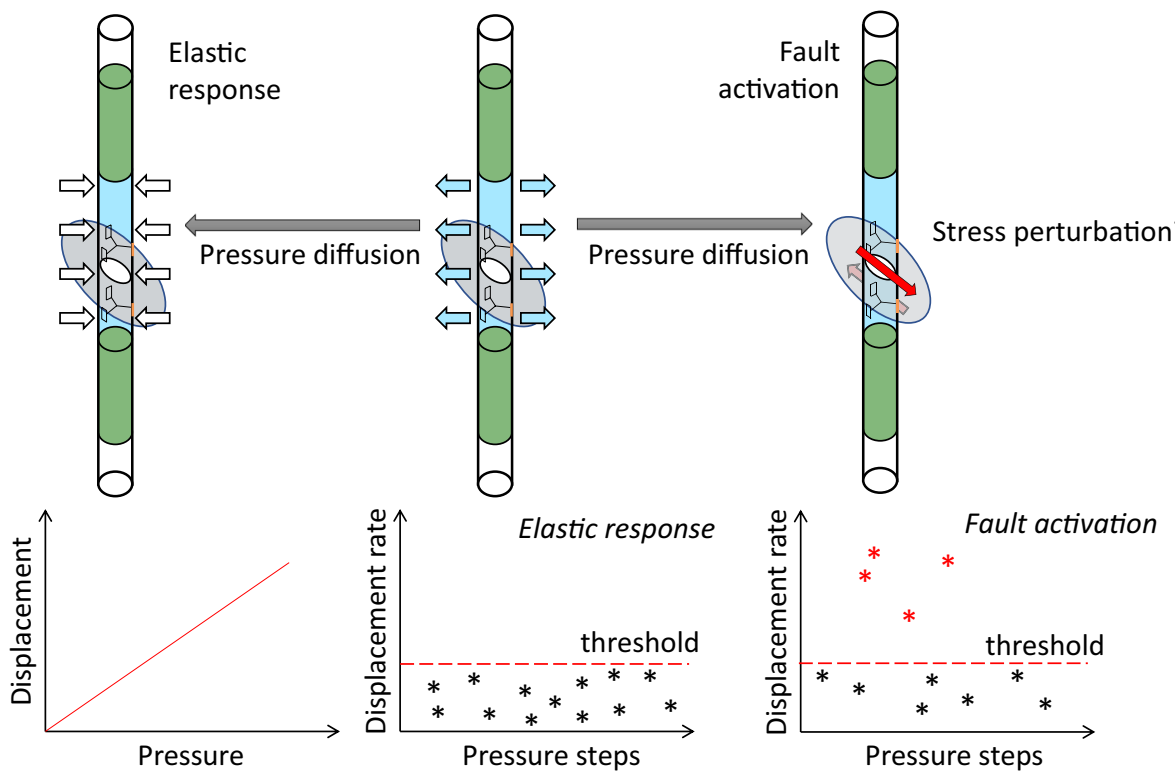

conclude that the first displacement events, or slip, occurred on the SE-dipping fractures. The variability in orientation and depth of the SE-dipping fractures requires further evaluation to define the exact orientation of the activated fracture.

At the LSBB URL, the first displacement vectors are subvertical and aligned with the sub-vertical fracture oriented $100^{\circ} / 70^{\circ}$. According to the regional stress by Guglielmi et al. (2015a), where the maximum stress is vertical, we conclude that this slip corresponds to the activation of the sub-vertical fracture. It is important to mention, that subvertical fractures are not optimally oriented for reactivation in pure shear. However, they still can be reactivated due to the relatively small difference between the stress magnitudes at the site's depth (Guglielmi et al. 2015a, b; Duboeuf 2018).

The bedding plane cannot be activated because of a low dip angle, and therefore, high normal stress. The activation of the bedding plane occurs at higher pressures ( $>4.3 \mathrm{MPa}$ ) and is associated with the seismic events. According to Duboeuf et al. (2017), seismicity was triggered by aseismic deformation. Therefore, the seismic activity of the bedding plane is triggered by the aseismic movement on the subvertical planes.

The orientations of the first sub-vertical displacements rotate with time until it gets to a constant high displacement rate and $105^{\circ} / 69^{\circ}$ orientation which contains a slip component on the sub-vertical fracture.

\subsection{The Comparison Between Behaviors of Shales at Mont Terri and Carbonates at the LSBB URL}

The highest differences in behavior during the injection between shales at Mont Terri and carbonates at the LSBB
URL lies in displacement response, injected flowrate, and associated seismicity.

For both rock types, the activation occurs at the end of the initial linear response. However, slip vectors do not demonstrate the maximum displacement rate. At Mont Terri this might be caused by the existence of another SW-dipping family of fractures that has strong mechanical interactions with SE-dipping fractures and affects the unperturbed slip evolution (Fig. 7b). At the LSBB URL, seismicity occurs 3 min after the first aseismic slip is observed, thus the seismic slip with the maximum displacement rate occurs in a stress state already perturbed by aseismic deformation (Duboeuf 2018; Duboeuf et al. 2017).

Seismicity is also one of the key parameters that differentiate the response of different experimental sites. No seismicity is observed at Mont Terri during the SRT injection. At the LSBB URL, 15 seismic events with an estimated magnitude lower than zero are observed during the injection (Duboeuf 2018; Duboeuf et al. 2017). The seismicity might be related to many parameters such as the difference in mineralogy, fracture stiffness, rock permeability, the amount of injected flowrate, rock brittleness, and stress state perturbation. Among all these, we clearly observe a strong difference in the injected flow rate variations between shales at Mont Terri and carbonates at LSBB URL. In shales, even if we observe some oscillations in the flow rate below $5 \mathrm{~L} / \mathrm{min}$, a rapid first injectivity increase up to $23 \mathrm{~L} / \mathrm{min}$ is observed above 5.8 MPa. Such a response to the fluid injection seems typical of the shales rock type with low permeability of $10^{-17}$ to $10^{-21} \mathrm{~m}^{2}$ (Henry et al. 2018, Jeanne et al. 2018). In carbonates of the LSBB URL, injectivity increases gradually, which is related to the high permeability of the rock 
mass up to $10^{-15} \mathrm{~m}^{2}$ (Cochard 2018; Jeanne et al. 2013). Moreover, carbonates may display a more brittle deformation than shales, which is more likely to favor seismicity.

\section{Conclusions}

Multiple and superposing processes involved during a fluid injection are related to the stress redistribution around the borehole, such as fluid diffusion within the rock mass, the elastic response of the rock and fractures, and the displacement occurring possibly on one or more fractures. We studied complex borehole 3D displacement signals during fault reactivation experiments and focused on isolating slip vectors that can be used for stress inversion. We identified two main phases in the rock mass response to injection:

- An initial linear relationship between pressure and displacement is related to the borehole compliant response to the injection.

- A second phase starting when the linearity is lost and some displacement starts to occur at a constant borehole pressure.

During this second phase we identified that displacement rate can be considered a reasonable proxy to isolate potential rupture events. Comparing tests in shales at Mont Terri and in carbonates in LSBB URL using the same protocol allowed us to discuss the validity of the first aseismic high rate event as the most representative of the virgin state of stress around the borehole. We observed that the following ones may depend on more complex interactions between stress, fluid diffusion and different geological heterogeneities. Thus, to simplify the interpretation of the coupled displacement-flowrate-pressure response after a fracture activation and to capture its slip vector, we developed a protocol that helps to distinguish slip vectors based on displacement rate. At the beginning of the test the low displacement rate is used to define a threshold. Any higher displacement rates are considered a potential rupture event. The orientation of the events is compared with the known fractures in the interval, enabling us to identify which fracture(s) was activated and to characterize the slip orientation. After identifying all the slip events within the interval, we assume that the first slip vectors would best represent the background stress (i.e., unperturbed stress state). The first slip we identify in both rock types occurs before induced seismicity if any. This observation raises concerns that stress inversions based on seismic data analyses may not be representative of in situ static stress but of dynamically perturbed stress. The counterpoint is that the static stress deduced from the first slip may still be in the borehole stress perturbation zone. Applying the protocol to more simple geologies and in deeper stress contexts with higher deviatoric stress is a promising perspective to calibrate this approach. In any case, adding the continuous borehole displacement monitoring to a fluid stimulation test appears to be a new method to track stress perturbation related to geological heterogeneity along with a deep borehole profile.

Acknowledgements Open access funding provided by University of University of Neuchâtel. This research is supported by the University of Neuchatel and the FS partners (swisstopo, ENSI, JAEA and LBNL). The experiment in carbonated was conducted within HYDROSEIS project (http://hydroseis.oca.eu) under contract ANR13-JS06-0004-01 and by Total SA (PI. through the HPMS-Ca project (Albion, PI. G. Massonat).

\section{Compliance with ethical standards}

Conflict of interest The authors declare that they have no conflict of interest.

Open Access This article is licensed under a Creative Commons Attribution 4.0 International License, which permits use, sharing, adaptation, distribution and reproduction in any medium or format, as long as you give appropriate credit to the original author(s) and the source, provide a link to the Creative Commons licence, and indicate if changes were made. The images or other third party material in this article are included in the article's Creative Commons licence, unless indicated otherwise in a credit line to the material. If material is not included in the article's Creative Commons licence and your intended use is not permitted by statutory regulation or exceeds the permitted use, you will need to obtain permission directly from the copyright holder. To view a copy of this licence, visit http://creativecommons.org/licenses/by/4.0/.

\section{Appendix}

See Tables 1 and 2 . 
Table 1 Characteristics of displacement events for steps 3, 7 and 8 at Mont Terri

\begin{tabular}{|c|c|c|c|c|c|c|}
\hline \multirow{2}{*}{$\begin{array}{l}\text { Pres- } \\
\text { sure } \\
\text { step }\end{array}$} & \multirow{2}{*}{$\begin{array}{l}\text { Displace- } \\
\text { ment } \\
\text { vectors }\end{array}$} & \multirow[t]{2}{*}{ Time of occurrence, $s$} & \multirow[t]{2}{*}{ Pressure, $\mathrm{MPa}$} & \multirow{2}{*}{$\begin{array}{l}\text { Displace- } \\
\text { ment rate, } \\
\mu \mathrm{m}\end{array}$} & \multicolumn{2}{|l|}{ Orientation } \\
\hline & & & & & Dip direction, ${ }^{\circ}$ & Dip angle, ${ }^{\circ}$ \\
\hline \multirow[t]{6}{*}{3} & 1 & 120.8 & 3.91 & 3.1 & 79 & 26 \\
\hline & 2 & 120.9 & 3.90 & 6.4 & 72 & 25 \\
\hline & 3 & 121.0 & 3.83 & 5.3 & 74 & 26 \\
\hline & 4 & 121.1 & 3.75 & 7.8 & 200 & 15 \\
\hline & 5 & 121.2 & 3.69 & 3.3 & 219 & 13 \\
\hline & 6 & 121.6 & 3.57 & 2.7 & 119 & -16 \\
\hline \multirow[t]{3}{*}{7} & 1 & 327.8 & 5.72 & 2.0 & 48 & -11 \\
\hline & 2 & 392.3 & 5.57 & 7.1 & 45 & -32 \\
\hline & $3-7$ & 393.9-397.7 & $5.56-5.58$ & $2.3-3.0$ & $315-340$ & $3-11$ \\
\hline \multirow[t]{4}{*}{8} & $1-6$ & $429.3-430.0$ & $6.22-6.23$ & $2.1-3.3$ & $148-194$ & $(-19)-17$ \\
\hline & $7-9$ & $432.8-430.0$ & 6.26 & $2.2-2.8$ & $281-313$ & $9-19$ \\
\hline & $10-26$ & $434.8-437.0$ & $6.04-6.22$ & $2.0-3.4$ & $140-229$ & $(-37)-2$ \\
\hline & $27-43$ & $437.6-439.2$ & $6.04-6.08$ & $2.2-3.9$ & $65-98$ & $(-28)-(-12)$ \\
\hline
\end{tabular}

Table 2 Characteristics of displacement events for steps 4, 10, 12 and 13 at the LSBB URL

\begin{tabular}{|c|c|c|c|c|c|c|}
\hline \multirow[t]{2}{*}{ Pres-sure step } & \multirow{2}{*}{$\begin{array}{l}\text { Displacement } \\
\text { vectors }\end{array}$} & \multirow[t]{2}{*}{ Time of occurrence, $\mathrm{s}$} & \multirow[t]{2}{*}{ Pressure, $\mathrm{MPa}$} & \multirow{2}{*}{$\begin{array}{l}\text { Displacement } \\
\text { rate, } \mu \mathrm{m}\end{array}$} & \multicolumn{2}{|l|}{ Orientation } \\
\hline & & & & & Dip direction, $^{\circ}$ & Dip angle,$^{\circ}$ \\
\hline 4 & $1-6$ & $228.4-228.9$ & $2.42-2.45$ & $2.5-3.3$ & Sub-vertical & \\
\hline \multirow[t]{6}{*}{10} & $1-3$ & $737.3-802.4$ & $4.36-4.39$ & $2.7-3.1$ & $106-131$ & $(-27)-(-17)$ \\
\hline & $4-5$ & $847.0-851.3$ & $4.36-4.37$ & $2.4-2.6$ & Sub-vertical & \\
\hline & 6 & 890.5 & 4.41 & 9.3 & 119 & -25 \\
\hline & 7 & 897.5 & 4.42 & 2.4 & Sub-vertical & \\
\hline & $8-11$ & $924.0-1110.5$ & $4.46-4.65$ & $2.9-9.0$ & $121-131$ & $(-29)-(-25)$ \\
\hline & 12 & 1328.0 & 4.73 & 2.7 & Sub-vertical & \\
\hline \multirow[t]{2}{*}{12} & $1-2$ & $1601.3-1601.4$ & 5.33 & $2.7-3.9$ & $91-95$ & -1 \\
\hline & 3 & 1669.5 & 5.34 & 2.4 & Sub-vertical & \\
\hline 13 & $1-2$ & $1674.6-1674.7$ & 5.90 & $2.7-3.3$ & $65-70$ & $(-2)-5$ \\
\hline
\end{tabular}

\section{References}

Avouac JP (2015) From geodetic imaging of seismic and aseismic fault slip to dynamic modeling of the seismic cycle. Annu Rev Earth Planet Sci 43:233-271

Barton CA, Zoback MD (1994) Stress perturbations associated with active faults penetrated by boreholes: possible evidence for nearcomplete stress drop and a new technique for stress magnitude measurement. J Geophys Res Solid Earth 99(B5):9373-9390

Bird P (1984) Hydration-phase diagrams and friction of montmorillonite under laboratory and geologic conditions, with implications for shale compaction, slope stability, and strength of fault gouge. Tectonophysics 107(3-4):235-260

Bott MHP (1959) The mechanics of oblique slip faulting. Geol Mag 96(2):109-117

Cappa F, Guglielmi Y, Nussbaum C, Birkholzer J (2018) On the relationship between fault permeability increases, induced stress perturbation, and the growth of aseismic slip during fluid injection. Geophys Res Lett (Oct). https://doi.org/10.1029/2018gl080233

Cappa F, Scuderi MM, Collettini C, Guglielmi Y, Avouac JP (2019) Stabilization of fault slip by fluid injection in the laboratory and in situ. Sci Adv 5(3):eaau4065
Cochard J (2018) Analysis of the reservoir properties of a fractured microporous carbonate series: integrated sedimentological, diagenetical and mechanical multiscalar approaches. Ph.D. Diss

Cornet FH (2012) Relation entre des mouvements sismiques et non sismiques induits par des injections de fluides sous pression. Hydrogeol J 20(8):1463-1466. https://doi.org/10.1007/s1004 $0-012-0901-z$

Cornet FH (2016) Seismic and aseismic motions generated by fluid injections. Geomech Energy Environ 5:42-54. https://doi. org/10.1016/j.gete.2015.12.003

Cornet FH, Helm J, Poitrenaud H, Etchecopar A (1997) Seismic and aseismic slips induced by large-scale fluid injections. Pure Appl Geophys 150(3-4):563-583. https://doi.org/10.1007/s000240050 093

De Barros L, Daniel G, Guglielmi Y, Rivet D, Caron H, Payre X, Bergery G, Henry P, Castilla R, Dick P et al (2016) Fault structure, stress, or pressure control of the seismicity in shale? Insights from a controlled experiment of fluid-induced fault reactivation. J Geophys Res Solid Earth 121(6):4506-4522 
Derode B, Guglielmi Y, De Barros L, Cappa F (2015) Seismic responses to fluid pressure perturbations in a slipping fault. Geophys Res Lett 42(9):3197-3203. https://doi.org/10.1002/2015G L063671

Duboeuf L (2018) Injections de fluide dans une zone de faille (LSBB, Rustrel): sismicité induite et déformation asismique. Ph.D. Diss

Duboeuf L, De Barros L, Cappa F, Guglielmi Y, Deschamps A, Seguy S (2017) Aseismic motions drive a sparse seismicity during fluid injections into a fractured zone in a carbonate reservoir. J Geophys Res Solid Earth 122(10):8285-8304. https://doi. org/10.1002/2017JB014535

Ellsworth WL (2013) Injection-induced earthquakes. Science 341(6142):1225942

Evans KF, Genter A, Sausse J (2005) Permeability creation and damage due to massive fluid injections into granite at $3.5 \mathrm{~km}$ at soultz: 1 . borehole observations. J Geophys Res Solid Earth 110(B4):1-19

Evans KF, Zappone A, Kraft T, Deichmann N, Moia F (2012) A survey of the induced seismic responses to fluid injection in geothermal and $\mathrm{CO}_{2}$ reservoirs in Europe. Geothermics 41:30-54. https://doi. org/10.1016/j.geothermics.2011.08.002

Gephart JW, Forsyth DW (1984) An improved method for determining the regional stress tensor using earthquake focal mechanism data: application to the San Fernando earthquake sequence. J Geophys Res Solid Earth 89(B11):9305-9320

Goodfellow SD, Nasseri MH, Maxwell SC, Young RP (2015) Hydraulic fracture energy budget: insights from the laboratory. Geophys Res Lett 42(9):3179-3187. https://doi.org/10.1002/2015GL0630 93

Goodman HE, Imbus SW, Espie T, Minnig C, Rösli U, Fierz T, Lettry Y (2017) Large rock mass experimentation @ mont terri underground research laboratory $-\mathrm{CO}_{2}$ containment assurance experiments. Energy Procedia 114(November 2016):5139_ 5150. https://doi.org/10.1016/j.egypro.2017.03.1668

Guglielmi Y (2016) Mont Terri Project. Technical note 2015-60. Phase 21. In-situ clay faults slip hydro-mechanical characterizatiom (FS experiment), Mont Terri underground rock laboratory. Tech. Rep. February

Guglielmi Y, Cappa F, Amitrano D (2008) High-definition analysis of fluid-induced seismicity related to the mesoscale hydromechanical properties of a fault zone. Geophys Res Lett 35(6):1-6. https://doi.org/10.1029/2007GL033087

Guglielmi Y, Cappa F, Lan, con H, Janowczyk JB, Rutqvist J, Tsang CF, Wang JSY (2013) ISRM suggested method for step-rate injection method for fracture in-situ properties (SIMFIP): using a 3-components borehole deformation sensor. In: The ISRM suggested methods for rock characterization, testing and monitoring: 2007-2014. Springer International Publishing, Cham, pp 179-186, https://doi.org/10.1007/978-3-319-07713-014

Guglielmi Y, Cappa F, Avouac JP, Henry P, Elsworth D (2015a) Seismicity triggered by fluid injection-induced aseismic slip. Science 348(6240):1224-1226. https://doi.org/10.1126/scien ce.aab0476

Guglielmi Y, Henry P, Nussbaum C, Dick P, Gout C, Amann F et al (2015b) Underground research laboratories for conducting fault activation experiments in shales. In: 49th US rock mechanics/geomechanics symposium, American Rock Mechanics Association

Guglielmi Y, Birkholzer J, Rutqvist J, Jeanne P, Nussbaum C (2017) Can fault leakage occur before or without reactivation? Results from an in situ fault reactivation experiment at Mont Terri. Energy Procedia 114(July):3167-3174. https://doi.org/10.1016/j.egypr o.2017.03.1445

Guglielmi Y, Nussbaum C, Jeanne P, Rutqvist J, Cappa F, Birkholzer J (2020) Complexity of fault rupture and fluid leakage in shale: insights from a controlled fault activation experiment. J Geophys Res Solid Earth 125(2):e2019JB017781
Henry P, Morereau A, Guglielmi Y (2018) Estimation of permeability in Mont Terri fault zone from FS experiments. In: Presentation at the Mont Terri conference in Nancy

Hubbert MK, Rubey WW (1959) Mechanics of fluid-filled porous solids and its application to overthrust faulting. Geol Soc Am Bull 70(2):115-166

Jaeggi D, Laurich B, Nussbaum C, Schuster K, Connolly P (2017) Tectonic structure of the Main Fault in the Opalinus Clay, Mont Terri rock laboratory (Switzerland). Swiss J Geosci 110(1):67-84

Jeanne P, Guglielmi Y, Lamarche J, Cappa F, Marié L (2012) Architectural characteristics and petrophysical properties evolution of a strike-slip fault zone in a fractured porous carbonate reservoir. J Struct Geol 44:93-109. https://doi.org/10.1016/j.jsg.2012.08.016

Jeanne P, Guglielmi Y, Cappa F (2013) Dissimilar properties within a carbonate-reservoir's small fault zone, and their impact on the pressurization and leakage associated with $\mathrm{CO}_{2}$ injection. J Struct Geol 47:25-35

Jeanne P, Guglielmi Y, Rutqvist J, Nussbaum C, Birkholzer J (2017) Field characterization of elastic properties across a fault zone reactivated by fluid injection. J Geophys Res Solid Earth 122(8):65836598. https://doi.org/10.1002/2017JB014384

Jeanne P, Guglielmi Y, Rutqvist J, Nussbaum C, Birkholzer J (2018) Permeability variations associated with fault reactivation in a claystone formation investigated by field experiments and numerical simulations. J Geophys Res Solid Earth 123(2):1694-1710

Kakurina M (2020) Mechanics of fault reactivation and its application to stress measurement. Ph.D. Diss

Kakurina M, Guglielmi Y, Nussbaum C, Valley B (2019) Slip perturbation during fault reactivation by a fluid injection. Tectonophysics $757: 140-152$

Laurich B, Sintubin M, Urai J (2015) Evolution of microstructure and porosity in faulted opalinus clay. Tech. rep., Lehr-und Forschungsgebiet GeologieEndogene Dynamik

Lei Q, Gao K (2019) A numerical study of stress variability in heterogeneous fractured rocks. Int J Rock Mech Min Sci 113:121-133

Lisle RJ (2013) A critical look at the Wallace-Bott hypothesis in fault-slip analysis. Bull Soc Geol Fr 184(4-5):299-306. https ://doi.org/10.2113/gssgfbull.184.4-5.299

Lund B, Slunga R (1999) Stress tensor inversion using detailed microearthquake information and stability constraints: application to Ölfus in southwest Iceland. J Geophys Res Solid Earth 104(B7):14947-14964. https://doi.org/10.1029/1999jb900111

Maerten L (2000) Variation in slip on intersecting normal faults: implications for paleostress inversion. J Geophys Res Solid Earth 105(B11):25553-25565. https://doi.org/10.1029/2000j b900264

Martin CD, Lanyon GW (2003) Measurement of in situ stress in weak rocks at Mont Terri Rock Laboratory, Switzerland. Int J Rock Mech Min Sci 40(7-8):1077-1088

McGarr A (2014) Maximum magnitude earthquakes induced by fluid injection. J Geophys Res Solid Earth 119(2):1008-1019

Nieto-Samaniego A, Alaniz-Alvarez S (1997) Origin and tectonic interpretation of multiple fault patterns. Tectonophysics 270(3-4):197206. https://doi.org/10.1016/S0040-1951(96)00216-8

Nussbaum C, Bossart P, Amann F, Aubourg C (2011) Analysis of tectonic structures and excavation induced fractures in the Opalinus Clay, Mont Terri underground rock laboratory (Switzerland). Swiss J Geosci 104(2):187

Pascal C (2002) Interaction of faults and perturbation of slip: influence of anisotropic stress states in the presence of fault friction and comparison between Wallace-Bott and 3D distinct element models. Tectonophysics 356(4):307-322. https://doi.org/10.1016/ S0040-1951(02)00413-4

Pollard D, Saltzer S, Rubin AM (1993) Stress inversion methods: are they based on faulty assumptions? J Struct Geol 15(8):1045-1054 
Reasenberg PA (1985) Fpfit, fpplot, and fppage: Fortran computer programs for calculating and displaying earthquake fault-plane solutions. US Geol Surv Open-File Rep, pp 85-739

Ruina A (1983) Slip instability and state variable friction laws. J Geophys Res 88(B12):10359-10370

Saffer DM, Marone C (2003) Comparison of smectite-and illite-rich gouge frictional properties: application to the updip limit of the seismogenic zone along subduction megathrusts. Earth Planet Sci Lett 215(1-2):219-235

Schoenball M, Dorbath L, Gaucher E, Wellmann JF, Kohl T (2014) Change of stress regime during geothermal reservoir stimulation. Geophys Res Lett 41(4):1163-1170. https://doi. org/10.1002/2013GL058514

Scholz CH (1998) Earthquakes and friction laws. Nature 391(6662):3742. https://doi.org/10.1038/34097

Segall P (1991) Fault mechanics. Rev Geophys Suppl 29:864-876

Shapiro SA, Dinske C (2009) Fluid-induced seismicity: pressure diffusion and hydraulic fracturing. Geophys Prospect 57(2):301-310. https://doi.org/10.1111/j.1365-2478.2008.00770.x

Shapiro SA, Audigane P, Royer JJ (1999) Large-scale in situ permeability tensor of rocks from induced microseismicity. Geophys J Int 137(1):207-213. https://doi.org/10.1046/j.1365-246X.1999.00781 . $\mathrm{x}$
Vavryčuk V (2014) Iterative joint inversion for stress and fault orientations from focal mechanisms. Geophys J Int 199(1):69-77. https ://doi.org/10.1093/gji/ggu224

Wallace RE (1951) Geometry of shearing stress and relation to faulting. J Geol 59(2):118-130. https://doi.org/10.1086/625831

Zoback MD, Harjes HP (1997) Injection-induced earthquakes and crustal stress at $9 \mathrm{~km}$ depth at the KTB deep drilling site, Germany. J Geophys Res Solid Earth 102(B8):18477-18491. https://doi. org/10.1029/96jb02814

Zoback MD, Kohli A, Das I, McClure M (2012) The importance of slow slip on faults during hydraulic fracturing stimulation of shale gas reservoirs. In: Society of Petroleum Engineers-SPE Americas Unconventional Resources Conference 2012 (2011), pp 344-352

Publisher's Note Springer Nature remains neutral with regard to jurisdictional claims in published maps and institutional affiliations. 